\title{
O financiamento e a gestão da EB: \\ a relação entre o público e o privado
}

\author{
Basic education financing and management: \\ the relationship between public and private
}

\section{La financiación y la gestión de EB: \\ la relación entre el público y el privado}

\section{MARINA SILVEIRA BONACAZATA SANTOS* \\ Universidade Estadual de Maringá, Maringá- PR, Brasil.}

JANI ALVES DA SILVA MOREIRA*

Universidade Estadual de Maringá, Maringá- PR, Brasil.

\begin{abstract}
RESUMO: O objetivo do texto é discutir sobre a relação entre o público e o privado no contexto das atuais políticas para a educação básica pública (EB) e suas implicações para o financiamento da educação. Destaca-se a influência das Organizações Sociais (OS) por meio da compreensão do contexto histórico e seus determinantes que forjam o tema abordado. O tema é atual, pois mecanismos de privatização, de terceirização e de parcerias entre os setores educacionais público e privado têm se intensificado, sendo relevante para o debate a sua problematização.
\end{abstract}

Palauras-chave: Políticas educacionais. Financiamento da educação.

Gestão da educação. Relação público versus privado.

ABSTRACT: The purpose of the text is to discuss the relationship between public and private in the context of the current policies for

* Graduanda em Ciências Biológicas pela Universidade Estadual de Maringá. Bolsista do Programa de Iniciação Científica (PIBIC/CNPq). Pesquisadora do Grupo de Estudos e Pesquisas em Políticas Educacionais, Gestão e Financiamento da Educação (GEPEFI). E-mail: <marina_bonacazata@hotmail.com>.

** Mestre e Doutora em Educação pela Universidade Estadual de Maringá. Docente Adjunta do Programa de Pós-Graduação em Educação e do Departamento de Educação da Universidade Estadual de Maringá. Líder do Grupo de Estudos e Pesquisas em Políticas Educacionais, Gestão e Financiamento da Educação (GEPEFI). E-mail: <professorajani@hotmail.com>. 
public basic education (EB) and its repercussions for the financing of education. The influence of the Social Organizations (OS) through the understanding of the historical context and its determinants that forge the theme addressed must be highlighted. The theme is contemporary, since mechanisms of privatization, outsourcing and partnerships between the public and private educational sectors have intensified, becoming its problematization appropriate for debating.

Keywords: Educational policies. Educational financing. Education management. Public vs. private relationship.

RESUMEN: El objetivo del texto es discutir sobre la relación entre lo público y lo privado en el contexto de las actuales políticas para la educación básica pública (EB) y sus implicaciones para la financiación de la educación. Se destaca la influencia de las Organizaciones Sociales (OS) por medio de la comprensión del contexto histórico y sus determinantes que dan forma al tema abordado. El tema es actual, pues mecanismos de privatización, de tercerización y de alianzas entre los sectores educacionales público y privado se han intensificado, siendo relevante para el debate su problematización.

Palabras clave: Políticas educacionales. Financiación de la educación. Gestión de la educación. Relación público versus privado.

\section{Introdução}

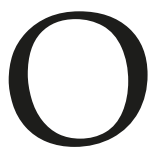

artigo refere-se aos resultados da pesquisa intitulada "As políticas de financiamento e a gestão da educação básica na relação público e privado: um estudo sobre as Organizações Sociais (OS)", realizada no ano de 2016, com apoio do Conselho Nacional de Pesquisa (CNPq). O objetivo dessa pesquisa foi compreender o tema de estudo por meio da inter-relação entre o momento histórico e as políticas definidoras do financiamento da educação básica pública para, posteriormente, apreender sobre as consequências da interligação das OS no âmbito da educação básica pública. Propôs-se uma análise crítica e documental das políticas públicas que definem o financiamento e a gestão da educação básica, com ênfase na influência das Organizações Sociais (OS). Convém ressaltar que a pesquisa configurou-se em uma análise crítica documental e de caráter bibliográfico, com destaque para o período histórico atual e a contextualização do objeto de estudo. 
Primeiramente, realizou-se uma conjectura das principais correntes políticas que influenciam as políticas públicas de financiamento da educação básica, por meio da compreensão sobre as determinações neoliberais e atuação da terceira via, perpassando pela compreensão da reforma do Estado e pela análise dos mecanismos provenientes das políticas de mercado estabelecidas no campo educacional. Em um segundo momento, discutiu-se a legislação educacional, a atuação das OS na educação básica pública, no qual abordou-se a configuração política, por meio da Constituição Federal de 1988 (BRASIL, 1988), Lei de Diretrizes e Bases da Educação (LDB) n 9.394/96 (BRASIL, 1996), da Lei № 13.005/2014 que instituiu o Plano Nacional da Educação (PNE) e a Lei № 13.204/2015 (BRASIL, 2015), que estabelece o regime jurídico das parcerias voluntárias, envolvendo ou não transferências de recursos financeiros entre a administração pública e as organizações da sociedade civil, como também define as diretrizes para a política de fomento e de colaboração com organizações da sociedade civil, institui o termo de colaboração e o termo de fomento. E, na sequência, fez-se uma análise da influência do Terceiro Setor da economia a fim de evidenciar a sua atuação nas determinações e ações políticas para a educação básica pública.

\section{Neoliberalismo, reforma do Estado e políticas mercadológicas na EB pública}

A partir da década de 1990, a política educacional brasileira passou a apresentar modificações na sua pauta de debates. Dentre os temas discutidos estiveram em destaque a autonomia escolar e a descentralização, lembrando que a relação entre o público e o privado é uma estratégia política presente na realidade do ensino público, que se intensificou a partir dessa década. Portanto, por meio dessa ligação, vem à tona a privatização de escolas públicas, com o objetivo propalado de melhorar a qualidade do ensino público.

Com a flexibilização da produção e nos moldes do modelo toyotista, intensificou-se a parceria público-privada, sendo uma maneira de intervenção dos recursos privados dentro da esfera pública com a transferência de funções que anteriormente eram atribuídas ao Estado e que, de acordo com a política da Terceira Via, por exemplo, são repassadas à sociedade civil. A expressão parceria público-privado implica a capacidade de intervenção do setor privado na esfera pública mediante a coordenação total ou parcial das responsabilidades até então atribuídas ao poder público. Nesse aspecto, Di Pietro adverte que:

[...] a reunião de esforços entre o Poder Público e o setor privado para a concretização de objetivos de interesse público, a partir de iniciativas legislativas (termo de parceria), bem como da sua aceitação pela doutrina no âmbito do Direito Público. Cabe ainda, nesta perspectiva, a designação de todas as formas de sociedade que, apesar de não formarem uma nova pessoa jurídica, se organizam entre os setores público e privado, para a consecução dos interesses públicos (DI PIETRO, 2005, p. 449). 
Osborne; Gaebler (1995), ao orientar para um governo empreendedor nos Estados Unidos, prescreveram orientações pautadas em medidas neoliberais para que as instituições públicas promovessem a flexibilidade necessária para reagir às condições complexas que mudam rapidamente. O que se torna difícil se os responsáveis pela condução política da comunidade usarem um único método, a prestação de serviços produzidos pela sua própria burocracia. Ese torna virtualmente impossível se os seus empregados não puderem ser transferidos de ocupação quando mudarem as demandas do público (OSBORNE; GAEBLER, 1995).

Nessa acepção, é evidente que o Brasil, em momentos de crise econômica e política, de forma ativada, retomou estratégias liberalizantes como uma válvula de escape e de ajuste. A política neoliberal utilizou-se de estratégias de ajustes estruturais neoliberais como a privatização, a terceirização e a publicização ${ }^{1}$ para a superação da crise. A saber, o neoliberalismo anuncia a menor intervenção possível do Estado na vida social, fornecendo à população somente os serviços essenciais e é nesse bojo que surgem as entidades de Terceiro Setor, como uma maneira de suprir a deficiência Estatal (COUTINHO, 2006, p. 25). Na visão de Ball (2014, p. 25 apud SHAMIR, 2008, p. 03), o neoliberalismo é um conjunto de medidas mercadológicas complexas e incoerentes:

[...] tratado nem como uma doutrina econômica concreta nem como um conjunto definido de projetos políticos. Pelo contrário, eu trato neoliberalismo como um conjunto complexo, muitas vezes incoerente, instável e até mesmo contraditório de práticas que são organizadas em torno de certa imaginação do "mercado" como base para "a universalização das relações sociais baseadas no mercado, com a correspondente penetração em quase todos os aspectos de nossas vidas, do discurso e/ou da prática de mercantilização, de acumulação de capital e de geração de lucros.

No governo de Fernando Henrique Cardoso (1995-2002) propuseram o Plano de Reforma do aparelho do Estado, apresentado pelo Ministério da Administração e Reforma do Estado (Mare), que foi defendida como resultado de política sob responsabilidade do ministro da Reforma Administrativa Luiz Carlos Bresser Pereira. De acordo com as orientações do ministro:

A reforma do Estado deve ser entendida dentro do contexto da redefinição do papel do Estado, que deixa de ser o responsável direto pelo desenvolvimento econômico e social pela via da produção de bens e serviços, para fortalecer-se na função de promotor e regulador desse desenvolvimento (BRASIL, 1995, p.12).

Outra frente política, o chamado Terceiro Setor, apresentou como solução da crise brasileira a política da Terceira Via, que visa não a minimização das atividades estatais, mas sim, auxiliar o Estado por meio de recursos privados. É nesse setor que estão inseridas as entidades sem fins lucrativos denominadas Organizações Sociais (OS).

No âmbito da atuação das OS, na pesquisa desenvolvida investigou-se a atuação do Instituto Ayrton Senna (IAS), caracterizado como uma Organização Social sem fins lucrativos que desenvolve diversas ações e programas, como o “Gestão Nota 10". O 
instituto se auto define como uma organização que trabalha para criar oportunidades de desenvolvimento humano a crianças e jovens brasileiros, em cooperação com empresas, governos, prefeituras, escolas, universidades e ONG. Sua metodologia trabalha com indicadores e metas gerenciais, capacitação dos profissionais em serviço e informação em tempo real (ADRIÃO et al., 2008, p.29).

Já no âmbito do financiamento educacional instalaram programas, como o Fundo de Financiamento Estudantil (Fies), destinado a financiar prioritariamente estudantes de cursos de graduação. Ainda, vale elencar o programa Universidade para Todos (Prouni), do Ministério da Educação, que concede bolsas de estudo integrais e parciais de $50 \%$ em instituições privadas de educação superior, em cursos de graduação e sequenciais de formação específica, a estudantes brasileiros sem diploma de nível superior. Voltado ao ensino profissional, é relevante o atual programa proposto pelo Governo federal, Programa Nacional de Acesso ao Ensino Técnico e Emprego (Pronatec)².

As OS fazem parte do Terceiro Setor e são autorizadas a estabelecer o contrato de gestão ${ }^{3}$. Na visão de Figueiredo (2003), as OS podem ser conceituadas como pessoas jurídicas privadas, sem fins lucrativos, cujas atividades, no âmbito federal, são dirigidas ao ensino, à pesquisa científica, ao desenvolvimento tecnológico, à proteção e à preservação do meio ambiente, à cultura e à saúde, atendendo aos requisitos previstos na Lei $\mathrm{n}^{\mathrm{o}}$ 9.637/98 (BRASIL, 1998).

Entre as principais características das OS, Brito (1998) apresenta a descentralização, já que há o envolvimento da sociedade, finalidade não lucrativa, autonomia administrativa, controle social, estabelecimento do contrato de gestão entre o Estado e a OS. Mediante essas características, as OS são autorizadas a realizar um contrato de gestão, na qual passam a ser fiscalizadas por receberem recursos públicos, fazendo uso de bens e funcionários da administração pública. $\mathrm{O}$ controle pode ser feito pelo poder público, mas, em geral, é o órgão ou entidade da administração pública que celebrou o contrato com a Organização Social que fica responsável por fiscalizá-la (BRASIL, 1998).

Na visão de Libanori; Riscal (2013), as OS são fundamentais para a parceria na realização dos programas, pois não pertencem apenas ao Estado, visto que são voltadas ao público, envolvendo a sociedade em suas ações. Vale ressaltar que o crescimento de parcerias com as OS foi uma das estratégias políticas neodesenvolvimentistas ${ }^{4}$ presentes no Brasil do século XXI, adotada pelos governos Lula da Silva e Dilma Rousseff, que buscaram priorizar políticas de recuperação do salário mínimo e de transferência de renda, cujo alvo a ser atingido era a classe baixa brasileira (BOITO JR., 2012).

Neste período, houve a participação de empresas internacionais como o Banco Nacional de Desenvolvimento Econômico (BNDES) para financiamento de grandes empresas nacionais brasileiras, a uma taxa de juro favorecida ou subsidiada, ou seja, favorecendo o crescimento e a valorização de empresas instaladas no Brasil para exportação de mercadorias e de capitais (DALLA COSTA, 2012). 
Segundo Boito Jr. (2012), a política neodesenvolvimentista brasileira, se referindo a era Lula e Dilma, além de envolver as diferentes classes, envolveu também estratégias populistas. Essa política foi controlada pelos mais favorecidos e buscou atingir a classe mais baixa da população brasileira, todavia, manteve intensas parcerias com setores privados (KOWARICK, 1975; NUN, 1978 e 2001).

Com o exposto fica visível que, de fato, a política brasileira passa por crises, ficando evidente o avanço da privatização no setor público no governo provisório ${ }^{5}$ atual, o que indica que as estratégias políticas neoliberais se sobressaem, conduzem ações e projetos e estão presentes na realidade atual brasileira.

\section{A legislação educacional, papel do Terceiro Setor e as OS na EB pública}

O artigo 206 da Constituição Federal (BRASIL, 1988) estabelece como necessário a coexistência dos setores público e privado na educação. De acordo com a Carta Magna, em seu Art. 170: “É assegurado a todos o livre exercício de qualquer atividade econômica, independentemente de autorização de órgão públicos, salvo nos casos previstos em lei". Este caso é também estabelecido no Art 7º da LDB nº 9.394/96 (BRASIL, 1996) ao instituir que o ensino é livre à iniciativa privadas atendidas as seguintes condições: I - cumprimento das normas gerais da educação nacional e do respectivo sistema de ensino; II - autorização de funcionamento e avaliação de qualidade pelo Poder Público; III - capacidade de autofinanciamento, ressalvado o previsto no Art. 213 da Constituição Federal. No Art. 19, a LDB estabelece que as instituições de ensino dos diferentes níveis classificam-se como públicas ou privadas, sendo a pública mantida e administrada pelo poder público.

A mesma lei estabelece que o Estado seja o responsável pela educação escolar pública, segundo o Art. $4^{\circ}$, no qual se estabelece que a educação básica deve ser obrigatória e gratuita dos 4 (quatro) aos 17 (dezessete) anos de idade, organizada da seguinte forma: a) pré-escola, b) ensino fundamental e c) ensino médio.

Outro ponto relevante é a atuação das entidades sem fins lucrativos na educação pública e a sua efetivação, por meio da Lei de Fomento de Parcerias ${ }^{6} n^{0}$ 13.204/2015 (BRASIL, 2015), que em seu artigo $2^{\circ}$ conceitua a OS como:

Entidade privada sem fins lucrativos que não distribua entre os seus sócios ou associados, conselheiros, diretores, empregados, doadores ou terceiros eventuais resultados, sobras, excedentes operacionais, brutos ou líquidos, dividendos, isenções de qualquer natureza, participações ou parcelas do seu patrimônio, auferidos mediante o exercício de suas atividades, e que os aplique integralmente na consecução do respectivo objeto social, de forma imediata ou por meio da constituição de fundo patrimonial ou fundo de reserva (BRASIL, 2015, p. 1). 
Nesse sentido, uma Organização Social estabelece as parcerias por meio de um Contrato de Gestão. Bresser Pereira, no contexto de reforma do Estado no governo de FHC, apresentava em seu documento intitulado Ministério da Administração Federal e Reforma do Estado (Mare), que as organizações sociais são vantajosas, embora se instalem sob o caráter de não possuírem fins lucrativos, ficando fora da administração pública (PEREIRA, 1997).

Em 2016, o estado de Goiás implantou um projeto de terceirização em que 23 escolas estaduais seriam administradas pelas OS, com o argumento de que tais instituições não possuem fins lucrativos, todavia, questiona-se sobre um barateamento nos custos e um ganho na qualidade e eficiência do ensino. Essa análise carece de avaliações, já que as OS de Goiás mostram baixa eficiência e qualidade, por possuírem funcionários com pouca experiência. Em 2017, uma liminar expedida pela juíza Eliana Xavier Jaime determinou a suspensão do edital que selecionou uma Organização Social (OS) para administrar escolas estaduais em Goiás. Ainda em março de 2018, outra OS não demonstrou capacidade técnica para gerir administração de escolas e a Procuradoria indeferiu o processo, mas, mesmo assim, foi qualificada como apta. ${ }^{7}$

Convém citar que em uma pesquisa desenvolvida pela revista Nova Escola, das dez organizações que estavam no processo de terceirização, cinco apresentavam menos de um ano de existência. Além disso, a maioria delas não conhecia o processo educacional a fundo, sem uma noção mínima do conceito de educação básica. De tal forma, as equipes de trabalhadores das instituições não são detalhadas quanto à função que cada pessoa executa, o que leva a pensar que não há um profissional com uma função específica (ACERVO, 2016).

A maioria das OS cadastradas no processo de terceirização não possui um site para expor todas as suas parcerias, gastos e projetos, o que é um dever, segundo a Lei № 13.204/15 ${ }^{8}$, nos Artigos 10 e 11, e algumas não informaram se possuem profissionais capacitados para o ensino.

Com a recente aprovação da Lei no $13.415 / 17$, com base no exposto em seus Arts. 6o e 7․ permitiu-se o "Notório Saber", conforme estabelece o Art.6 ${ }^{\circ}$, inciso IV “[...] profissionais com notório saber reconhecido pelos respectivos sistemas de ensino, para ministrar conteúdos de áreas afins à sua formação ou experiência profissional, atestados por titulação específica ou prática de ensino em unidades educacionais da rede pública ou privada ou das corporações privadas em que tenham atuado [...]". Essa permissão desencadeou o surgimento de organizações sociais que promoverão a formação do professor de forma aligeirada, como a intitulada "Ensina Brasil" que propagandeia formar um educador em apenas cinco semanas de treinamento (AVALIAÇÃO EDUCACIONAL, 2016).

A lei que regulamenta a atuação das OS, no Brasil, é a Lei federal nº 9.637, de 15 de maio de 1998, a qual dispõe, entre outros assuntos, sobre a delimitação de suas áreas de atuação, a saber: ensino; pesquisa científica; desenvolvimento tecnológico; proteção e preservação do meio ambiente; cultura e saúde. Percebe-se que a adoção do sistema das 
OS no ensino nem sempre garante uma elevação na qualidade de ensino e de profissionais, pois, como o exposto na pesquisa, a maioria dos professores não possuía experiência mínima com a educação.

O Terceiro Setor e as OS, segundo os moldes neoliberais, propõe estabelecer uma política de parceria que garanta a melhoria da qualidade do ensino público. Como já foi dito, por Terceiro Setor entende-se aquele que congrega as organizações que não pertencem ao Estado e não possuem fins lucrativos (RESENDE, 2009).

Desde o contexto de reestruturação produtiva do capital, a partir da década de 1973, foi visível que o Brasil enfrentou uma crise do capital que levou ao aumento da inflação e ao baixo crescimento econômico. De acordo com Peroni; Oliveira; Fernandes (2009), no contexto da reforma do Estado é que se nota a ampliação da atuação do Terceiro Setor, que abrange as OS. A partir do governo de FHC (1995-1998), as parcerias público-privado ficaram mais evidentes (ALVES; SEVERINO, 2011).

Sistematizada por Anthony Giddens, a Terceira Via tem como objetivo a reorganização do sistema capitalista, por meio de mudanças na política e economia dos países. A Terceira Via se coloca contra o Estado mínimo, já que visa auxiliar o Estado (NEVES, 2005). Para a Terceira Via, os neoliberais não estão de todo errados, já que eles defendem a intervenção do mercado para estimular a economia e não a atuação do Estado (NEVES, 2005). Segundo Neves, de acordo com uma pesquisa do Instituto Brasileiro de Geografia e Estatística (IBGE), as OS justificam sua importância devido ao trabalho voluntário, servindo como fonte de emprego para pessoas que se encontram fora do mercado de trabalho, devido à crise que o País está a enfrentar em todos os setores.

Essas entidades, nas análises de Neves (2005), injetam na atualidade cerca de 17,5 bilhões na economia provenientes de pagamento de salário e de remunerações. As ONG empregam 1,54 milhões de trabalhadores assalariados com um salário médio de 871 reais, (2005, p. 122). As ONG abrigam também os trabalhadores informais que trabalham por conta e não são registrados em carteira.

Nesse sentido, o Instituto Ayrton Senna (IAS), criado em 20 de novembro de 1994, é um exemplo de organização do Terceiro Setor, sem fins lucrativos, que desenvolve consultorias de gestão de negócios, faz diagnósticos, propõe soluções, desenvolve treinamento de pessoal, mas não implanta os seus projetos, ficando essa responsabilidade para as secretarias de educação de cada Estado e o controle das metas a serem estabelecidas a cargo da direção da escola (OLIVEIRA; PINTO, 2013). Os autores mencionam que um dos programas que o IAS apoia é o chamado "Gestão Nota 10". O programa direciona a atuação da gestão das escolas públicas por meio de metas que são estabelecidas pelo IAS, para melhorar a capacitação dos professores e a qualidade do ensino em quatro eixos:

Os indicadores para o sucesso do ensino fundamental, segundo o IAS seguem quatro eixos, sendo eles: gestão da aprendizagem (preocupação com a quantidade e qualidade do aluno); gestão do ensino (preocupação com a qualidade do trabalho 
do professor); gestão da rotina escolar (corresponde ao dia-a-dia da escola, do fazer escolar, organização da sala de aula, controle e frequência administrativa etc.) e gestão da política pública (visa a intencionalidade do governo na afirmação de programas e projetos sociais (OLIVEIRA; COUTINHO, 2014, p. 138).

De acordo com Oliveira; Coutinho (2014), o problema é que as escolas não têm contato com o IAS e com as secretarias de educação. O IAS se reúne com as secretarias de educação e orienta, prestando consultorias e informações do alcance ou não das metas, ao diretor da escola, que encaminha aos professores o que deve ou não ser melhorado e alcançado.

Os autores apresentam o relato de uma escola que afirmou que o programa não atendeu aos seus interesses e nem propôs a autonomia necessária, pois a escola continua trabalhando com uma realidade de 45 alunos por sala, com falta constante de professores, sem material, professores desmotivados, alunos indisciplinados, pais omissos e secretaria de educação distante da escola. Em suma, os autores analisam que o programa "Gestão Nota 10 " até pode melhorar a educação em questão quantitativa se conseguir cumprir todas as metas propostas, mas não garante a qualidade do ensino-aprendizagem, visto que o professor não tem liberdade para pensar sua prática pedagógica.

Outra instituição do Terceiro Setor que essa pesquisa analisou foi o Instituto Unibanco (IU), que "realiza o projeto "jovem de futuro" 9 e foi fundado no ano de 1982, com o objetivo de criar, de produzir e de desenvolver investimentos sociais do grupo Unibanco. Desse modo, a partir do ano de 2008, por meio de uma fusão, passou a incorporar o grupo do Banco Itaú, integrando parte das OS do grupo Itaú Unibanco e atuando como um dos encarregados pelo seu investimento social" (BALDUINO, 2016, p. 70).

Segundo o autor, o IU integra, atualmente, o movimento denominado Todos Pela Educação, organizado a partir de empresas brasileiras, como Grupo Gerdau, Grupo Suzano, Banco Itaú, Banco Bradesco e as Organizações Globo, o Instituto Ayrton Senna, entre outros (2016). O IU tem suas ações voltadas para jovens com baixa renda que frequentam o ensino médio das escolas públicas, concebendo, validando e disseminando tecnologias e metodologias sociais ${ }^{10}$ (INSTITUTO UNIBANCO, 2010).

Na visão do IU (2009), os baixos níveis de renda, limitam o aprendizado e as oportunidades de trabalho para as pessoas mais pobres, portanto é fundamental manter esses jovens nas escolas:

Longe da filantropia e sem assumir papéis que substituam ou se confundam com a ação do Estado, [o Instituto] concentra sua ação no estabelecimento de Parcerias Público-Privadas que contribuam para melhorar a ação dos governos em suas políticas sociais e principalmente a educação (INSTITUTO UNIBANCO, 2009, p. 16).

As ações do IU se voltam para as escolas públicas mais especificamente para o ensino médio das escolas estaduais, com o objetivo de maior qualidade do ensino, mas também com o foco no mercado de trabalho (INSTITUTO UNIBANCO, 2009). Sendo 
assim, percebe-se a crescente influência da política da Terceira Via, aplicada por meio do Terceiro Setor, em parcerias firmadas tanto com as organizações sem fins lucrativos (OS) quanto com organizações associadas à sociedade civil, ou seja, públicas não estatais, de direito privado.

O Projeto Jovem de Futuro foi implantado em 2007, em caráter experimental, em três escolas paulistanas. No ano seguinte (2008), expandiu-se e o IU formalizou a proposta como projeto piloto em 20 instituições de ensino de Minas Gerais e 22 do Rio Grande do Sul. Segundo Balduíno (2016), em 2009, o projeto se "ampliou para mais 41 escolas do estado de São Paulo, sendo 21 na região metropolitana da capital e 20 em municípios da região do Vale do Paraíba". Em 2010, se encerrou a implantação do programa em 20 escolas do estado de Minas Gerais e 22 do estado do Rio Grande do Sul (INSTITUTO UNIBANCO, 2010). Até 2018, o Programa “Jovem de Futuro” estará presente em 2500 escolas e atingirá 2 milhões de estudantes (INSTITUTO UNIBANCO, 2016). Em resumo, o impacto do projeto:

\footnotetext{
[...] mostrou que os alunos das escolas de intervenção tiveram avanços significativos em relação aos do grupo de controle. As médias em língua portuguesa e matemática no Saeb (Sistema de Avaliação da Educação Básica) dos estudantes das escolas a tendidas atingiram um nível de proficiência que, sem a ação do Jovem de Futuro, exigiria pelo menos mais três anos de estudos [...] também proporcionou a melhoria na gestão escolar, além de contar, ao longo dos três anos da ação, com a participação ativa de alunos e da comunidade em iniciativas de melhoria do ambiente escolar (INSTITUTO UNIBANCO, s.d., p. 10).
}

Pode-se cotejar que o papel das OS e o Terceiro Setor tem abarcado a educação pública como um campo de disputa e de negócios que tem favorecido, na visão de Ball (2014), a uma desestatização proposital da educação pública. Segundo o autor essas iniciativas do Terceiro Setor revelam ambições e as visões mercadológicas das empresas que atuam no sistema de ensino público moldadas a atritos econômicos, convertendo bens públicos e privados, que acabam promovendo a educação como uma área de negócios, impondo valores competitivos e assumindo "[...] papéis dentro do discurso e da infraestrutura da reforma, convertendo política educacional em um diferente tipo de linguagem, investida com diferentes tipos de relações , interesses e fins"' (BALL, 2014, p. 200).

\section{Considerações finais}

Assim, ao destacar a relação entre os setores público e privado para a educação básica pública e as implicações para o seu financiamento, evidencia-se duas principais frentes políticas enquadradas como tentativas para a superação da crise estrutural do capital que o Brasil enfrentou: o neoliberalismo e o Terceiro Setor. O primeiro, a favor da privatização e da mínima atuação do Estado, já o segundo, por sua vez, defende a política 
da Terceira Via, que visa a colaborar com o Estado, por meio do investimento de capital privado em benefício da melhoria do ensino público.

Com base nisso, ao analisar alguns programas desenvolvidos pelo Terceiro Setor, como os implantados pelo IAS e IU, percebeu-se que houve a inserção de mais pessoas no campo educacional, entretanto, não há certeza da qualidade do ensino promovido e orientado por essas ações. No caso específico do programa Gestão Nota 10, no Maranhão, vê-se que ele não atende aos seus interesses e nem dá autonomia necessária, pois a escola continua a trabalhar com uma realidade de 45 alunos por sala, há falta de professores e de material didático, além dos educadores estarem desmotivados e da presença de alunos indisciplinados, com pais omissos, bem como a falta de contato entre a secretaria de educação do estado e a escola (OLIVEIRA; COUTINHO, 2014).

Assim, ao tomar por base o exposto, conclui-se que a adoção das OS no sistema de ensino público não garante sua melhoria. As OS são, portanto, uma estratégia de contenção de gastos no sistema público de ensino. Por meio da convergência entre o setor público e privado, as OS estão destinadas a fornecer soluções rápidas para os problemas considerados difíceis no setor público, sob a perspectiva dos negócios exercida no campo dos problemas sociais e educacionais. Mediante Ball (2014, p. 122), estamos a vivenciar um contexto de crescimento da "filantropia de risco", que está assentada em três princípios de trabalho: na ampliação e adequação das organizações sem fins lucrativos, comprometendo grandes lotes de financiamento por longos períodos de tempo, com a ênfase na avaliação e na gestão de desempenho; e ainda na promoção de relações "investidor-investido", com base em engajamento consultivo.

Recebido em: 30/09/2017, reapresentado em: 02/05/2018 e aprovado em: 19/07/2018

\section{Notas}

1 Privatização é a passagem dos serviços lucrativos para o mercado; terceirização é o processo de transferência para o setor privado de serviços auxiliares ou de apoio e publicização, a "transferência para o setor público não estatal dos serviços sociais e científicos que hoje o Estado presta”" (BRESSER-PEREIRA, 1997, p.7-8).

2 O Programa Nacional de Acesso ao Ensino Técnico e Emprego (Pronatec) poderá ainda ser executado com a participação de entidades privadas sem fins lucrativos, devidamente habilitadas, mediante a celebração de convênio, acordo, contrato, ajuste ou instrumento congênere, observada a obrigatoriedade de prestação de contas da aplicação dos recursos nos termos da legislação vigente (BRASIL, art. 6, 2011).

3 O contrato de gestão é um compromisso institucional, firmado entre o Estado, por intermédio de seus ministérios, e uma entidade pública estatal, a ser qualificada como agência executiva, ou uma entidade não estatal, qualificada como Organização Social. O instrumento firmado entre o poder público e a entidade qualificada como Organização Social, com vistas à formação de parceria entre as partes para fomento e execução de atividades relativas às áreas relacionadas no art. 1ํo (BRASIL, 1998). 
4 Usa-se o termo desenvolvimentista por causa do desenvolvimento do capitalismo por meio de transferência de renda, sem romper com o neoliberalismo que vigorava no País. Nos governos de Lula e Dilma usaram-se técnicas como políticas de recuperação do salário mínimo e de transferência de renda, que aumentaram o poder aquisitivo das camadas mais pobres, forte elevação da dotação orçamentária do Banco Nacional de Desenvolvimento Econômico (BNDES) para financiamento das grandes empresas nacionais a uma taxa de juro favorecida ou subsidiada, entre outras medidas.

5 Nos referimos ao governo de Michel Temer instituído após o impeachment da presidente Dilma Rousseff. “O processo de impeachment de Dilma Rousseff teve início em 2 de dezembro de 2015, quando o ex-presidente da Câmara dos Deputados Eduardo Cunha deu prosseguimento ao pedido dos juristas Hélio Bicudo, Miguel Reale Júnior e Janaína Paschoal. Com uma duração de 273 dias, o caso se encerrou em 31 de agosto de 2016, tendo como resultado a cassação do mandato, mas sem a perda dos direitos políticos de Dilma". Disponível em < https://www12.senado.leg.br/noticias/materias/2016/12/28/impeachment-de-dilma-rousseff-marca-ano-de-2016-no-congresso-e-no-brasil> Acesso em 27 de maio de 2018.

6 O termo parceria significa um conjunto de direitos, responsabilidades e obrigações decorrentes de relação jurídica estabelecida formalmente entre a administração pública e organizações da sociedade civil, em regime de mútua cooperação, para a consecução de finalidades de interesse público e recíproco, mediante a execução de atividade ou de projeto expressos em termos de colaboração, em termos de fomento ou em acordos de cooperação (Lei de Fomento de Parcerias no 13.204/2015).

7 Sobre essa problemática encontram-se diversas notícias na Rede Internet. Ver: RESENDE, Paula. Após liminar, escolas iniciam ano letivo sem a gestão de OS em Goiás. Disponível em http://g1.globo.com/ goias/noticia/2017/01/apos-liminar-escolas-iniciam-ano-letivo-sem-gestao-de-os-em-goias.html Acesso em 27 de maio de 2018.

8 Lei que alterou a Lei de Fomento de Parcerias nำ 13.019/2014.

9 O programa Jovem de Futuro foi apresentado em 2006, com o objetivo de oferecer às escolas públicas de ensino médio regular apoio técnico e financeiro para a concepção, implantação e avaliação de um plano de melhoria de qualidade, com duração de três anos, que vise, através de estratégias de incentivo a professores e alunos e de melhoria do ambiente físico, aumentar significativamente o rendimento dos alunos, nos testes padronizados de Português e Matemática, e diminuir os índices de evasão escolar. Em 2010 se encerrou a implantação do programa (INSTITUTO UNIBANCO, s.p.).

10 Por tecnologia o Instituto define o "Conjunto integrado de propostas de ação, capazes de funcionar, de forma sinérgica, na melhoria da qualidade das escolas públicas de Ensino Médio. Estas articulam diferentes metodologias e, para validar sua efetividade, são testadas em várias escolas, com acompanhamento e supervisão intensiva [...]". E define metodologia como "parte de uma tecnologia e podem ser oferecidas de maneira independente, visando à intervenção em aspectos específicos da vida do jovem ou da realidade escolar. Elas constituem estratégias complementares de melhorias de resultados e também passam por testagem, em caráter experimental, quando são aferidos seus resultados, mas sem envolver necessariamente avaliações de impacto [...]" (INSTITUTO UNIBANCO, 2010, p. 19).

\section{Referências}

ACERVO NOVA ESCOLA. Exclusivo: quem vai administrar as escolas de Goiás? Disponível em: http://acervo.novaescola.org.br/politicas-publicas/radiografia-oss-goias-938045.shtml. Revista Nova Escola, [online]: Fundação Lemann. Acesso em: 21 de junho 2016.

ADRIÃO, Theresa; PERONI, Vera. (Coord.). Análise das consequências de parcerias firmadas entre os municípios brasileiros e a Fundação Ayrton Senna. Rio Claro: Instituto de Biociências- UNESP, 2008. Projeto financiado pelo CNPq. 
AGÊNCIA BRASIL. Qualificação de organizações sociais da educação em Goiás começou em 2015. Disponível em: http://agenciabrasil.ebc.com.br/educacao/noticia/2016-01/organizacoes-sociais-daeducacao-comecaram-ser-qualificadas-no-ano-passado . Acesso em: 22 de junho 2017.

ALVES, Andrêssa Gomes de Rezende; SEVERINO, Jorismary Lescano. "Terceiro setor" e educação: configurações, impasses e perspectivas. 25ํㅗ Simpósio Brasileiro e 20 Congresso Ibero-Americano de Política e Administração da Educação. - 2011.

AVALIAÇÃO EDUCACIONAL. "Notório saber": vire professor em 5 semanas. Revista Avaliação Educacional. Disponível em: https://avaliacaoeducacional.com/2016/09/24/notorio-saber-vireprofessor-em-5-semanas/. Acesso em: 25 de outubro 2016.

BALDUINO, Maria Aparecida Canale. Programa Jovem de Futuro: uma proposta do terceiro setor para a gestão de escolas do ensino médio na rede estadual de ensino de Mato Grosso do Sul (2012-

2014). 2016. 186 f. Tese (Doutorado) - Curso de Doutorado em Educação, Programa de Pós- Graduação em Educação, Universidade Católica Dom Bosco, Campo Grande, 2016.

BALL, Stephen. J. Educação Global S.A.: novas redes políticas e o imaginário neoliberal. Tradução: Janete Bridon. Ponta Grossa: UEPG, 2014.

BRITO, Frederico Durão. Reinventando as Instituições. Revista do Ministério da Administração Federal e Reforma do Estado, Brasília, n. 1, p. 14-21, maio de 1998.

BRASIL. MEC. FIES - Apresentação. Disponível em: http://portal.mec.gov.br/index.php?option=com_ content\&view=article\&id=198\&Itemid=303. Acesso em: 22 de junho 2017.

Pronatec. Disponível em: http://portal.mec.gov.br/pronatec. Acesso em: 21 de junho 2017.

Constituição da República Federativa do Brasil de 1988. Disponível em: http://www.planalto. gov.br/ccivil_03/Constituicao/Constituicao.htm. Acesso em: 21 de junho 2017.

Lei no 9.394, de 20 de dezembro de 1996. Disponível em: http://www.planalto.gov.br/ccivil_03/ leis/L9394.htm. Acesso em: 22 de junho 2017.

Lei no 9.637, de 15 de maio de 1998. Disponível em: http://www.planalto.gov.br/ccivil_03/leis/ L9637.htm. Acesso em: 22 de junho 2017.

Lei no 13.204, de 14 de dezembro de 2015. Disponível em: http://www.planalto.gov.br/ ccivil_03/_ato2015-2018/2015/lei/113204.htm. Acesso em: 22 de junho 2017.

BOITO Jr., Armando As bases políticas do neodesenvolvimentismo. Fórum Econômico da FGV / São Paulo, edição de 2012. Disponível em: http://bibliotecadigital.fgv.br/dspace/bitstream/ handle/10438/16866/Painel\%203\%20\%20Novo\%20Desenv\%20BR\%20\%20Boito\%20\%20Bases\%20 Pol\%20Neodesenv\%20\%20PAPER.pdf?sequence=1. Acesso em: 21 de junho 2017.

A natureza da crise política brasileira. Le Monde Diplomatique - Brasil [online]. Número 104. p., março de 2016. Disponível em: http://www.adunicamp.org.br/wp-content/uploads/2016/03/ Le_Monde_Diplomatique_Brasil_2016_Reduzido.pdf. Acesso em: 21 de junho 2017.

CEDES.UNICAMP. Plano Nacional de Educação 2014-2024 [recurso eletrônico]: Lei nº 13.005, de 25 de junho de 2014, que aprova o Plano Nacional de Educação (PNE) e dá outras providências. - Brasília: Câmara dos Deputados, Edições Câmara, 2014. 86 p. - (Série legislação; no 125). Disponível em: http:// www.cedes.unicamp.br/dl/1IASbwjA0_MDA_b189e_. Acesso em: 21 de junho 2017.

COUTINHO, Nina Novaes. As organizações sociais e o contrato de gestão. Revista de Direito Público, Londrina: UEL, v. 1, n. 2, p.25-40, mai./ago. 2006. 
DALLA COSTA, Armando et al. Desenvolvimento e crise na América Latina. Estado, empresas e sociedade. Curitiba: Editora CRV, 2012.

DI PIETRO, Maria Sylvia Zanella. Parcerias na administração pública: concessão, permissão, franquia, terceirização e outras formas. São Paulo: Atlas, 2005.

FIGUEIREDO, Lúcia Valle. Curso de Direito Administrativo. São Paulo: Malheiros, 2003.

INSTITUTO UNIBANCO. Jovem de Futuro. Disponível em: http://www.institutounibanco.org.br/ jovem-de-futuro/. Acesso em: 21 de junho 2017.

KOWARICK, Lucio. Capitalismo e marginalidade na América Latina. Rio de Janeiro: Paz e Terra, 1975.

NEVES, Lúcia Maria Wanderley (Org.). A nova pedagogia da hegemonia: estratégias do capital para educar o consenso. São Paulo: Xamã, 2005.

NUN, José. Superpopulação relativa, exército industrial de reserva e massa marginal. In: PEREIRA, Luiz. (Org). Populações Marginais. São Paulo: Duas Cidades, 1978.

OLIVEIRA, Ildoana Paes.; COUTINHO, Adelaide Ferreira. O “Terceiro Setor" e a execução de programas educacionais: a parceria entre o Governo do Maranhão e o Instituto Ayrton Senna no Projeto Gestão Nota 10. Revista Educação e Emancipação, São Luís: UFMA, v. 7, n. 1, p.129-146. jan./jun. 2014.

OLIVEIRA, Ildoana Paz; PINTO, Maisa Cunha. O terceiro setor e a gestão da educação: adoção do Programa Gestão Nota 10 pelo Governo do Estado do Maranhão como estratégia de melhoria dos indicadores sociais da educação. VI Jornada Internacional de Políticas Públicas, Cidade Universitária da UFMA, São Luís/Maranhão - Brasil, 2013.

OSBORNE, D.; GAEBLER, T. Reinventando o governo: como o espírito empreendedor está transformando o setor público. Brasília: MH Comunicação, 1995.

PEREIRA, Bresser. Cadernos MARE da reforma do Estado. 1997. Disponível em: http://www. bresserpereira.org.br/documents/mare/cadernosmare/caderno02.pdf. Acesso em: 21 de junho 2017.

PERONI, Vera Maria Vidal; OLIVEIRA, Regina Tereza Cestari de; FERNANDES, Maria Dilnéia Espíndola. Estado e terceiro setor: as novas regulações entre o público e o privado na gestão da educação básica brasileira. Educ. Soc. Campinas: Cedes, v. 30, n. 108, p.761-778, out. 2009.

PROUNI. O que é o Prouni? Disponível em: http://siteprouni.mec.gov.br/. Acesso em: 27 de setembro 2016.

RESENDE, Tomáz de Aquino. Terceiro Setor, ONGs e Institutos. Disponível em: http://www.fundata.org. br/Artigos\%20\%20Cefeis/12\%20\%20TERCEIRO\%20SETOR,\%20ongs.pdf. Acesso em: 21 de junho 2017.

RISCAL, Sandra; LIBANORI, Guilherme. A Constituição das unidades escolares como executoras das políticas públicas por meio de parcerias entre estado e organizações sociais. RBPAE, Capinas: UFRGS v. 29, n. 1, p. 45-60, jan./abr. 2013. Disponível em: http://seer.ufrgs.br/index.php/rbpae/article/ view/42820/27120. Acesso em: 22 de junho 2017. 